\title{
The Estimate of Aerosol Optical Depth for Diverse Meteorological Conditions
}

\author{
Foued Chabane $^{1,3^{*}}$, Ali Arif ${ }^{2}$, Said Benramache ${ }^{3}$ \\ ${ }^{1}$ Department of Mechanical Engineering, Faculty of Technology, University of Biskra, Biskra 07000, Algeria \\ ${ }^{2}$ Department of Electrical Engineering, Faculty of Technology, University of Biskra, Biskra 07000, Algeria \\ ${ }^{3}$ Department of Physic, University of Biskra, Biskra 07000, Algeria
}

Corresponding Author Email: fouedmeca@ hotmail.fr

https://doi.org/10.18280/i2m.190206

Received: 14 November 2019

Accepted: 27 February 2020

\section{Keywords:}

aerosol optical depth, wave, climate, prediction, temperature

\begin{abstract}
The dependence of aerosol optical depth on wavelength as well as the fit of the humidity, temperature, and pressure approximation has been investigated under air mass at location Biskra city of Algeria. The study is based on spectral data acquired with both spectral wavelength: 550 and $1250 \mathrm{~nm}$. Under clear conditions, aerosols are the main atmospheric components responsible for direct effects on solar radiation. Measurements of aerosol optical properties along with simultaneous measurements of global solar irradiances were recorded at an urban site (Biskra, Algeria) to characterize the radiative effect of atmospheric aerosols from January to December 2013. This relationship constitutes an alternative tool for estimating AOD from routine irradiance measurements available from numerous radiometric stations worldwide. The results of the proposed model were compared with the experimental data and there was an excellent correlation between the results obtained. We conclude in this study with a good result between measurement data and prediction which done a perfect approximation with a great convergent.
\end{abstract}

\section{INTRODUCTION}

Aerosols play important role in the balance of the Earth's climate. Due to the increasing anthropogenic emission of aerosols since the industrial revolution, they can also effect the global climate change. However, the effects of aerosols on climate are not one-way, moreover excessively uncertain. The climate forcing by aerosols can be realized in two ways, basically: in direct and indirect radiative forcing. As the direct solar radiation passes through the atmosphere, it is attenuated by two main physical processes: scattering (angular redistribution of energy) and absorption (conversion of energy into either heat or photochemical change). Both effects are known to be wavelength dependent [1]. Atmospheric aerosols affect the earth's radiation budget directly by scattering and absorbing solar and terrestrial radiation, and indirectly by modifying the physical and radiative properties of clouds [2].

Meteorological surface observations constitute a potential source of information on the past atmospheric aerosol load. Wang et al. [3], for example, used visibility observations as a proxy for studying the evolution of the aerosol optical depth (AOD) over land since 1973, while Ohvril et al. [4] used measurements of the direct solar radiation at various stations in Russia, Ukraine, and Estonia for estimating the atmospheric transparency, a quantity that can be translated into AOD. The oldest data included in the study by Ohvril et al. [4] date back to 1906. Unfortunately, such data exist only for few selected stations. Atmospheric aerosols influence the Earth's climate by modifying its energy balance through the direct, indirect and semi-direct effects. However, the uncertainty of aerosol effects on the Earth's radiation budget greatly exceeds that of any other climate forcing agent $[5,6]$. This is due to the fact that the aerosol physical, chemical and optical properties are highly. Some researchers have used the solar irradiation as source energy of solar collector. Therefore, it can be concluded that solar irradiation has a great effect on the thermal efficiency of solar collectors [7-16].

With the rapid development of global economy, the challenges for environment and energy are more and more severe. Concentrating solar power, more commonly referred to as CSP [17-20], is unique among solar energy generators.

Some study interested to investigate the possibility of using coupled meteorology-aerosol data assimilation (DA) to improve the forecast of a dust storm, and interfaced a coupled meteorology-chemistry model (WRF-Chem) with a hybrid variational-ensemble DA system. The results indicate that meteorological observations can partially contribute to the change of aerosol initial conditions and vice versa, implying a cross-component impact of observations, and hence improving the utility of observations in coupled DA [21]. Other researchers have presented study focuses on the application of stochastic modeling technique in analyzing the future trends of aerosol optical properties. The stochastic behavior of Terra-MODIS AOD550 nm data over mega city New Delhi [22]. The Bristow-Campbell model has also been improved by considering the factors influencing the incoming solar radiation, such as relative humidity, cloud cover, etc. The authors indicate that there are large differences in model accuracies for each model at different stations, the ANN models can estimate daily $\mathrm{Hg}$ with satisfactory accuracy at most stations in different climate zones, and MLP and RBNN models provide better accuracy than the GRNN and IBC models, for example, the MAE and RMSE values range 1.53- 
2.29 and 1.94-3.27 $\mathrm{MJ} \mathrm{m}^{2}$ day $^{-1}$, respectively for MLP model [23].

Some results validated by MODIS-Terra versus the Aerosol Robotic Network AOD550 revealed that the former underestimated aerosol loading over the studied regions due to uncertainties in surface reflectance. The spatial seasonal distributions of mean AOD550 suggested high values during the local dry periods. Furthermore, latitudinal and longitudinal gradients in AOD550 showed a southern low and northern high and a western low and eastern high profile, respectively during JJA, as other seasons showed heterogeneous variations [24].

In the above literatures, the effect of the aerosol on the solar radiation for different meteorological conditions is limited and difficult. In this paper, the performance of AOD in many meteorological conditions (i.e., clear day, Humidity, and Temperature, Rainfall and air pressure) has been investigated. The main idea of this paper is: Firstly, the AODs for two wavelengths in many meteorological conditions have been experimented based on the site located in Biskra, Algeria; Secondly, global solar radiation have been calculated according to AODs, and the aim is to obtain relationship between all meteorological conditions.

\section{METHODOLOGY}

\subsection{Aerosol optical depth}

Aerosol optical depth is a determine of the extinction of the solar beam by dust and haze. In other words, particles in the atmosphere (dust, smoke, pollution) can block sunlight by absorbing or by scattering light. AOD tells us how much direct sunlight is prevented from reaching the ground by these aerosol particles. It is a dimensionless number that is related to the amount of aerosol in the vertical column of atmosphere over the observation location.

A value of 0.01 corresponds to an extremely clean atmosphere, and a value of 0.4 would correspond to a very hazy condition. An average aerosol optical depth for the Biskra in all month is 0.08 to 0.4 .

\subsection{Calculating aerosol optical thickness}

The intensity $I$ of a narrow beam of sunlight of a particular wavelength that reaches Earth's surface is given by

$$
I=I_{o} \times \exp (\lambda \times m)
$$

where, Io is the intensity of sunlight just above Earth's atmosphere, $(\lambda)$ is the total atmospheric optical thickness, and $m$ is the relative air mass. $m=1$ when the sun is directly overhead and is otherwise approximately equal to $\sec (\mathrm{z})$, where $\mathrm{z}$ is the solar zenith angle [25].

\subsection{Prediction of aerosol optical depth}

The variation of an aerosol optical depth corresponding to urban of Biskra is taking according to global solar irradiation for all month of the year and then trying to fit the global solar irradiation on the horizontal area as function to aerosol optical depth in a both spectral wave $550 \mathrm{~nm}$ and $1250 \mathrm{~nm}$.

About the climate of Biskra is changing according to meteorology, so we try to fitting the aerosol optical depth by the temperature, humidity, pressure, wind speed and rainfall; when find the perfect function automatically select the constants of parameters which determinate according the influence of phenomena; in this article we can choose the power function.

$$
\begin{array}{r}
\left(\mathrm{AOD}_{550}, \mathrm{AOD}_{1240}\right)=a \times \mathrm{BCAOD}_{550}^{\mathrm{b}} \times \mathrm{DUAOD}_{550}^{c} \times \\
\operatorname{OMAOD}_{550}^{\mathrm{d}} \times \operatorname{SSAOD}_{550}^{\mathrm{e}} \times \\
\operatorname{SUAOD}_{550}^{\mathrm{f}}
\end{array}
$$

Table 1 shows the constants of the aerosol optical depth by spectral wavelength 550 and $1240 \mathrm{~nm}$ it's determined according to components of the total aerosol optical depth of the black carbon, dust, organic matter, sea salt, and sulfate.

Residual squar for $\mathrm{AOD}_{550}$ and $\mathrm{AOD}_{1240}$ same to 0.9839 and 0.9916 , respectively.

$$
\left(\mathrm{AOD}_{550}, \mathrm{AOD}_{1240}\right)=a_{1} \times T^{b_{1}} \times H r^{c_{1}} \times P^{d_{1}} \times W^{e_{1}} \times R a^{f_{1}}
$$

Residual squar for $\mathrm{AOD}_{550}$ and $\mathrm{AOD}_{1240}$ same to 0.8064 and 0.7665 , respectively.

\section{RESULTS AND DISCUSSION}

Figure 1 shows the variation of the aerosol optical depth as a function to the number of the month, the evolution according to three curves for each curves represents the total aerosol optical depth corresponding to both wavelength 550 $\mathrm{nm}$ and $1240 \mathrm{~nm}$, and the last curves is aerosol optical depth of dust in the site of Biskra. We can see that the AOD of 550 $\mathrm{nm}$ take a maximum value of the AOD 1240nm. The minimum value is registering in January and December, increasing upward to reach in the month of June and July. The variation of AOD is a same variation of solar radiation in all month.

The aerosol optical depth of Sulfate in the wavelength 550 $\mathrm{nm}$ take a maximum value versus to Black carbon, organic matter and sea salt see Figure 2. We observed that the aerosol optical depth of sea salt takes a maximum value between January and March and then decrease to last month December. In February the both AOD of sea salt and Sulfate take a similar same value as in March. The AOD of Black carbon it's varying according the variation of solar radiation and it is too a less value of other aerosols optical depth, and about AOD of organic matter it is taking a maximum value in July and a minimum in November.

Table 1. The constants of the aerosol optical depth corresponding to wavelength 550 and $1240 \mathrm{~nm}$

\begin{tabular}{ccccccc}
\hline Aerosol optical depth & $\boldsymbol{a}$ & $\boldsymbol{b}$ & $\boldsymbol{c}$ & $\boldsymbol{d}$ & $\boldsymbol{e}$ & $\boldsymbol{f}$ \\
\hline AOD $_{50}$ & 1.392 & 0.153 & 0.615 & -0.0501 & 0.0575 & -0.084 \\
AOD $_{1240}$ & 0.632 & 0.119 & 0.881 & -0.179 & 0.119 & -0.265 \\
\hline
\end{tabular}




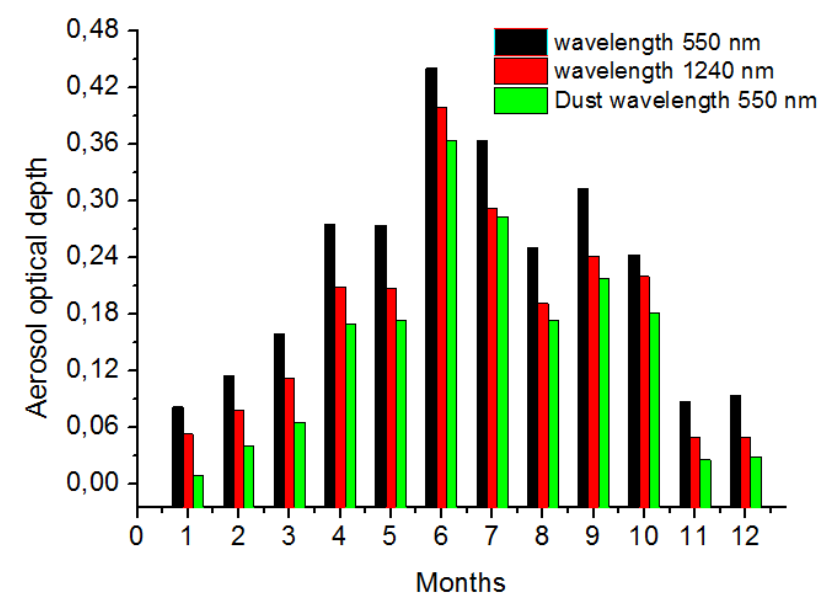

Figure 1. Total aerosols Optical Depth of AOD (550 and $1240 \mathrm{~nm})$ and Dust AOD (550 nm)

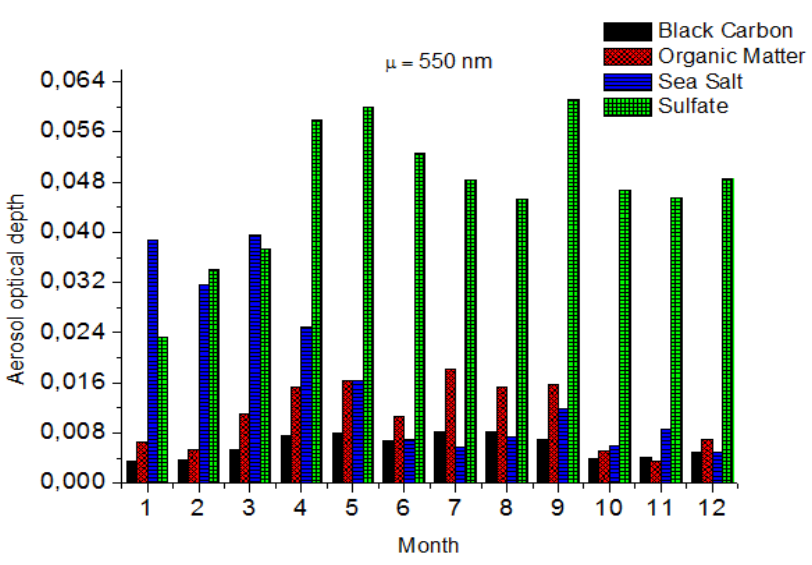

Figure 2. Aerosols Optical Depth of AOD (550 nm), Black Carbon, Organic Matter, sea salt and sulfate

The curves of the Figure 3 show the variation of both parameters temperature and relative humidity as a function to number of month. We can see the dependability of temperature and relative humidity with inverse variation; the temperature air take a minimum value in the first month January and December and then in a maximum value in July on the other hand the relative humidity it's varying to inverse a minimum in July and a maximum in January and December. The temperature and relative humidity in July $\mathrm{T}=306.65 \mathrm{~K}$ and $\mathrm{Hr}=24.4 \%$, respectively, in this point the total aerosols optical depth AOD550 $=0.3635$ and AOD1240 $=0.291$, when the global solar radiation $\mathrm{G}=1006 \mathrm{~W} / \mathrm{m}^{2}$ in $12 \mathrm{~h} 00$. We can be selected the relative humidity and ambient temperature by Eqns. (4) and (5) which as function to number of the months.

$$
H r=71.51-13.89 \times N_{m}+1.0757 \times N_{m}^{2} \quad R^{2}=0.953
$$

$$
T=269.65+9.63 \times N_{m}-0.696 \times N_{m}^{2} \quad R^{2}=0.857
$$

The wind blows because of differences in air pressure from one location to another. Wind blows from areas of high pressure toward areas of low pressure see Figure 4. If the high pressure area is very close to the low pressure area, or if the pressure difference is very great, the wind can blow very fast. About this difference is result another influence in the aerosol optical depth by the transport from point to another point, we can said that the air pressure has a big role in this effect. So we wanted to make our prediction of aerosol optical depth linked to the weather see Eq. (3) and Table 2 and the pressure correlation according to Eq. (6).

$$
\begin{aligned}
P= & 1008-6.54 N_{m}+0.12 N_{m}^{2}+0.31 N_{m}^{3}-0.045 N_{m}^{4}+ \\
& 0.0018 N_{m}^{5} \quad R^{2}=0.81
\end{aligned}
$$

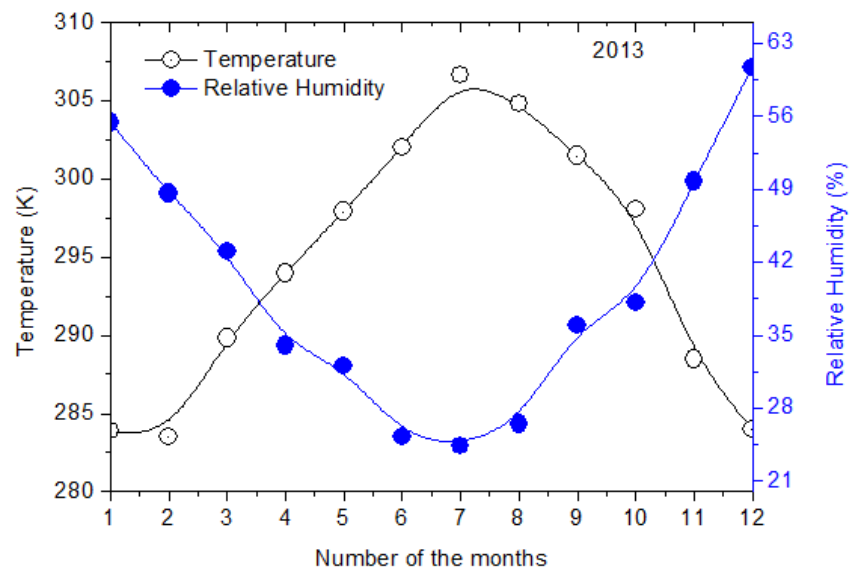

Figure 3. Ambient temperature and relative humidity of air in Biksra

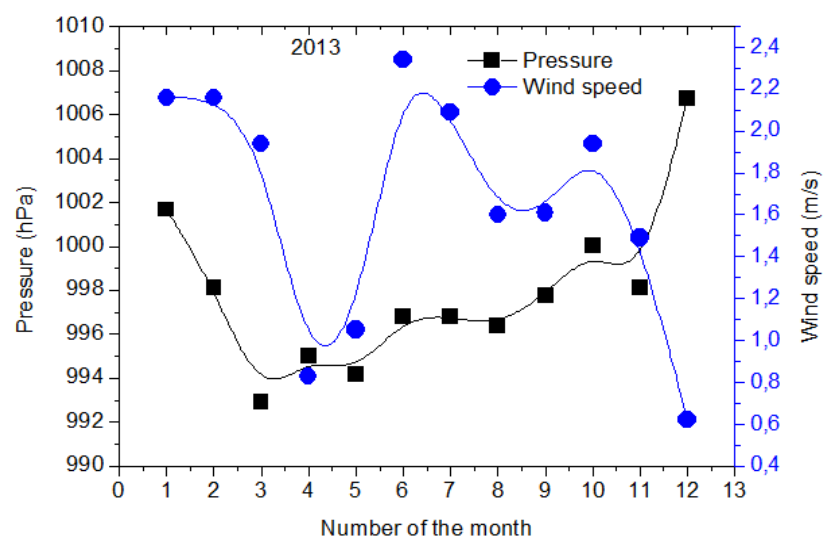

\begin{tabular}{|c|c|c|c|c|c|c|}
\hline Aerosol optical depth & $a_{1}$ & $b_{1}$ & $c_{1}$ & $d_{1}$ & $e_{1}$ & $\overline{f_{1}}$ \\
\hline $\mathbf{A O D}_{550}$ & $\begin{array}{c}0.361 \\
\text { E-5 }\end{array}$ & 0.218 & -1.649 & 2.254 & 0.1 & 0.0543 \\
\hline AOD $_{1250}$ & 0.00164 & -3.391 & -2.13 & 4.544 & 0.233 & 0.0522 \\
\hline
\end{tabular}

Figure 4. Wind speed and pressure of air in Biskra

Table 2. The constants of the aerosol optical depth corresponding to wavelength 550 and $1240 \mathrm{~nm}$ according to temperature, humidity, pressure and rainfall 


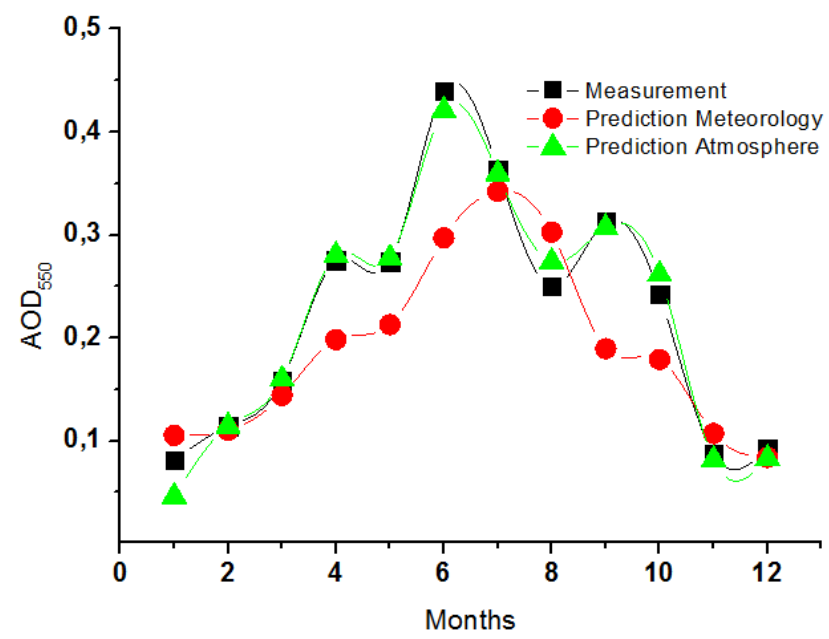

Figure 5. Wind speed and pressure of air in Biskra

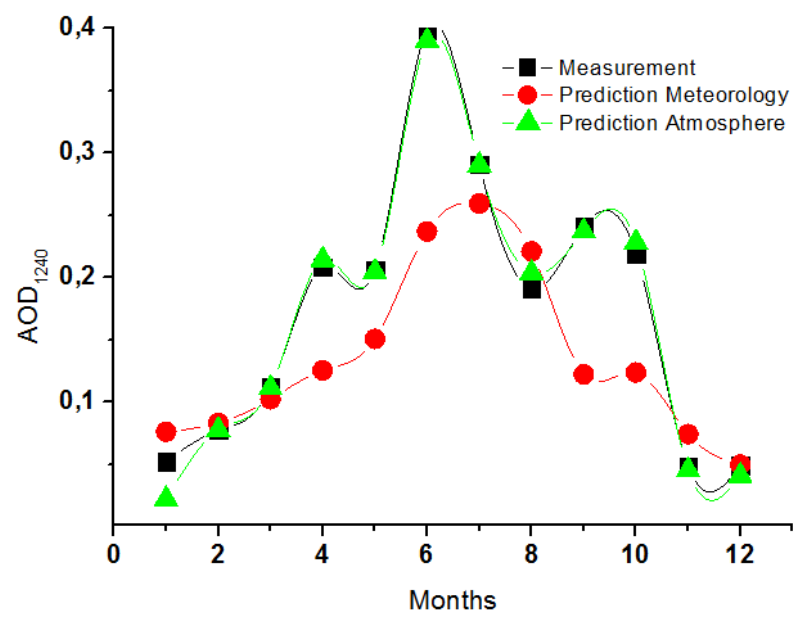

Figure 6. Wind speed and pressure of air in Biskra

Figures 5 and 6 represent changes in aerosol optical depth for the wavelength of 550 and $1240 \mu \mathrm{m}$ in terms of the number of months per year. We studied the comparison of measured values and predictions of two types for climate and the second for weather. We observed that the curve of the aerosol optical depth both in wavelengths in 550 and 1240 are identical with the curve for atmosphere forecasting and are close to that of the meteorelogy curve.

\section{CONCLUSION}

The researchers today need to predict some parameters before they do the experimental study, such as the simulation or numerical modeling some physic phenomena. So in this points trying to create a good approximate of aerosols optical depth with perfect relationship between many parameters such as weather climate and some components of pollution in the atmosphere like.

We conclude in this study with a good result between measurement data and prediction which done a perfect approximation with a great convergent.

Finally, we made us the aerosols optical depth varying between many parameters; such as temperature, relative humidity, wind speed, air pressure, and rainfall and aerosols optical depth. AODs increases with decreasing wavelength for all meteorological conditions.

\section{REFERENCES}

[1] El-Shobokshy, M.S., Al-Saedi, Y.G. (1993). Atmospheric turbidity and transmittance of solar radiation in Riyadh, Saudi Arabia. Atmospheric Environment. Part B. Urban Atmosphere, 27(4): 401411. https://doi.org/10.1016/0957-1272(93)90017-Z

[2] Charlson, R.J., Langner, J., Rodhe, H., Leovy, C.B., Warren, S.G. (1991). Perturbation of the northern hemispheric radiative balance by back scattering from anthropogenic surface aerosols. Tellus, 43(4): 152-163. https://doi.org/10.1034/j.1600-0870.1991.00013.x

[3] Wang, K., Dickinson, R.E., Liang, S. (2009). Clear sky visibility has decreased over land globally from 1973 to 2007. Science, 323(5920): 1468-1470. https://doi.org/10.1126/science. 1167549

[4] Ohvril, H., Teral, H., Neiman, L., Kannel, M., Uustare, M., Tee, M., Russak, V., Okulov, O., Joeveer, A., Kallis, A., Ohvril, T., Terez, E. I., Terez, G. A., Gushchin, G. K., Abakumova, G. M., Gorbarenko, E.V., Tsvetkov, A.V., Laulainen, N. (2009). Global dimming and brightening versus atmospheric column transparency. Europe, 1906-2007. J. Geophys. Res.-Atmos., 114(D10). https://doi.org/10.1029/2008JD010644.

[5] Kaufman, Y., Tanré, D., Boucher, O. (2002). A satellite view of aerosols in the climate system. Nature, 419: 215-223. https://doi.org/10.1038/nature01091

[6] Vardavas, I.M., Taylor, F.W. (2011). Radiation and Climate: Atmo-Spheric Energy Budget from Satellite Remote Sensing. International Series of Monographs on Physics No. 138, Oxford University Press, Oxford.

[7] Chabane, F., Moummi, N., Benramache, S. (2014). Experimental study of heat transfer and thermal performance with longitudinal fins of solar air heater. Journal of Advanced Research, 5(2): 183-192. https://doi.org/10.1016/j.jare.2013.03.001

[8] Chabane, F., Moummi, N., Benramache, S., Tolba, A.S. (2012). Experimental study of heat transfer and an effect the tilt angle with variation of the mass flow rates on the solar air heater. International Journal of Science and Engineering Investigations, 1(9): 61-65.

[9] Chabane, F., Moummi, N., Benramache, S. (2012). Experimental performance of solar air heater with internal fins inferior an absorber plate: In the region of Biskra. Journal of Energy Resources Technology, 4(33): 1-6.

[10] Chabane, F., Moummi, N., Brima, A., Benramache, S. (2013). Thermal efficiency analysis of a single-flow solar air heater with different mass flow rates in a smooth plate. Frontiers in Heat and Mass Transfer, 4(1): 013006. https://doi.org/10.5098/hmt.v4.1.3006

[11] Chabane, F., Moummi, N., Benramache, S., Bensahal, D., Belahssen, O. (2013). Collector efficiency by single pass of solar air heaters with and without using fins. Engineering Journal, 17(3): 43-55. https://doi.org/10.4186/ej.2013.17.3.43

[12] Chabane, F., Moummi, N., Benramache, S. (2012). Effect of the tilt angle of natural convection in a solar collector with internal longitudinal fins. International Journal of Science and Engineering Investigations, 1(7): 13-17.

[13] Chabane, F., Moummi, N., Benramache, S. (2013). Experimental analysis on thermal performance of a solar air collector with longitudinal fins in a region of 
Biskra, Algeria. Journal of Power Technologies, 93(1): 52-58.

[14] Chabane, F., Moummi, N., Benramache, S., Belahssan, O., Bensahal, D. (2014). Nusselt number correlation of SAH. Journal of Power Technologies, 93(2): 100-110.

[15] Chabane, F., Moummi, N. (2014). Heat transfer and energy analysis of a solar air collector with smooth plate. European Physical Journal Applied Physics, 66(1): 10901. https://doi.org/10.1051/epjap/2014130405

[16] Chabane, F., Hatraf, N., Moummi, N. (2014). Experimental study of heat transfer coefficient with rectangular baffle fin of solar air heater. Frontiers in Energy, 8(2): 160-172. https://doi.org/10.1007/s11708014-0321-y

[17] Stückle, A., Laing, D., Müller-steinhagen, H. (2014). Numerical simulation and experimental analysis of a modular storage system for direct steam generation. Heat Transfer Engineering, 35: 812-821. https://doi.org/10.1080/01457632.2013.828556

[18] Bauer, T., Pfleger, N., Breidenbach, N., Eck, M., Laing, D., Kaesche, S. (2013). Material aspects of solar salt for sensible heat storage. Applied Energy, 111: 1114-1119. https://doi.org/10.1016/j.apenergy.2013.04.072

[19] Laing, D., Bahl, C., Bauer, T., Fiss, M., Breidenbach, N., Hempel, M. (2012). High-temperature solid-media ther-mal energy storage for solar thermal power plants. Proceedings of the IEEE, 100(2): 516-524. https://doi.org/10.1109/JPROC.2011.2154290

[20] Boxwell, M. (2012). Solar Electricity Handbook: A Simple. Practical Guide to Solar Energy, pp. 41-42.

[21] Lee, E., Županski, M., Županski, D., Park, S.K. (2017). Impact of the OMI aerosol optical depth on analysis increments through coupled meteorology-aerosol data assimilation for an Asian dust storm. Remote Sensing of Environment, 193:

38-53. https://doi.org/10.1016/j.rse.2017.02.013

[22] Taneja, K., Ahmad, S., Ahmad, K., Attri, S.D. (2016). Time series analysis of aerosol optical depth over New Delhi using Box Jenkins ARIMA modeling approach. Atmospheric Pollution Research, 7(4): 585-596. https://doi.org/10.1016/j.apr.2016.02.004
[23] Wang, L.C., Kisi, O., Zounemat-Kermani, M., Salazar, G.A., Zhu, Z.M, Gong, W. (2016). Solar radiation prediction using different techniques: model evaluation and comparison. Renewable and Sustainable Energy Reviews, 61: 384-397. https://doi.org/10.1016/j.rser.2016.04.024

[24] Boiyo, R., Kumar, K.R., Zhao, T.L., Bao, Y.S. (2017). Climatological analysis of aerosol optical properties over East Africa observed from space-borne sensors during 2001-2015. Atmospheric Environment, 152: 298-313. https://doi.org/10.1016/j.atmosenv.2016.12.050

[25] McCartney, J. (1976). Optics of the Atmosphere. John Wiley and Sons, New York, NY, USA.

\section{NOMENCLATURE}

BCAOD Black Carbon of aerosol optical depth

OMAOD Organic Matter of aerosol optical depth

DUAOD Duct of aerosol optical depth

SSAOD sea salt of aerosol optical depth

SUAOD sulfate of aerosol optical depth

Io intensity of sunlight just above Earth's atmosphere $\left(\mathrm{W} / \mathrm{m}^{2}\right)$

$\lambda \quad$ total atmospheric optical thickness

$\mathrm{m} \quad$ relative air mass

intensity of a narrow beam of sunlight of a particular wavelength that reaches Earth's surface $\left(\mathrm{W} / \mathrm{m}^{2}\right)$

$\mathrm{a}, \mathrm{b}, \mathrm{c}, \mathrm{d}, \mathrm{e}$ constants according to predicted model and $\mathrm{f} \quad$ corresponding to atmospheric parameters

$\mathrm{a}_{1}, \mathrm{~b}_{1}, \mathrm{c}_{1}, \mathrm{~d}_{1}$, constants according to predicted model $\mathrm{e}_{1}$ and $\mathrm{f}_{1} \quad$ corresponding to meteorology parameters

$\mathrm{T} \quad$ ambient temperature $(\mathrm{K})$

$\mathrm{Hr} \quad$ relative humidity $(\%)$

$\mathrm{P} \quad$ pressure $(\mathrm{hPa})$

W Wind speed $(\mathrm{m} / \mathrm{s})$

$\mathrm{Ra} \quad$ rainfall $(\mathrm{mm})$

$\mathrm{N}_{\mathrm{m}} \quad$ nomber of the month

$\mathrm{R}^{2} \quad$ residual square 